Gut, 1987, 28, S1, 217-220

\title{
Distribution of gastrointestinal hormones in the adaptive response after small bowel transplantation
}

\author{
E DELTZ, J H GEBHARDT, Ch PREISSNER, P SCHROEDER, M L HANSMANN, \\ E KAISERLING, H K MÜLLER-HERMELINK, AND A THIEDE \\ From the Depts of General Surgery, and Pathology, University of Kiel, and Dept of Pathology, University of \\ Würzburg, Federal Republic of Germany
}

SUMMARY Enteroendocrine regulatory peptides may play an important role in the adaptation of small bowel mucosa, and it is likely that they act interdependently with neural and luminal stimuli. We assessed their action in rats by morphometric evaluation of enteroendocrine cells after heterotopic accessory small bowel transplantation (SBT), in which the graft is shunted off from the intestinal passage and is entirely deprived of neural connections, and after orthotopic SBT with normal intestinal passage. Sections of the jejunum and the ileum of the graft were immunostained with antibodies to cholecystokinin (CKK), neurotensin (NT) and vasoactive intestinal peptide (VIP). The amount and distribution of positive cells was assessed semiquantitatively. Three weeks after SBT in the heterotopic graft there was a marked decrease in CCK and NT positive cells and VIP positive fibres in the entire organ, compared with the controls. Histological examination revealed that villi and crypts had atrophied. After orthotopic SBT the number of CCK and NT positive cells increased and exceeded normal values by $20-40 \%$. VIP positive fibres did not reach normal amounts. No mucosal atrophy was detected. These findings support the view that the intrinsic neurohormonal system is reestablished in the grafted small bowel and that enteroendocrine regulatory peptides may act as trophic factors that are responsible for adaptation after SBT.

It is likely that the control of the adaptive response and the transport capacity of small bowel mucosa depends on the interaction of neural, enteroendocrine, and luminal stimuli. ${ }^{1-3}$ Enteroglucagon has been suggested to be an effective agent for influencing growth after small bowel resection. ${ }^{1-5}$ After small intestinal bypass and small bowel resection gastric inhibitory peptide (GIP) shows a strong reaction. Buchan and coworkers ${ }^{6}$ found a markedly reduced number of GIP positive cells in the functional jejunum after jejunoileal bypass and in the jejunum of rat after massive small bowel resection. In addition there is evidence that other gastrointestinal peptides play a significant role in the gastrointestinal regulatory systems that influence the transporting epithelium of the small bowel mucosa. In the rat model exclusion of nutritional stimuli to the small bowel mucosa during total parenteral nutrition (TPN) causes a marked decrease in cholecystokinin (CCK) positive cells in the duodenum and a decrease in neurotensin (NT)

Address for correspondence: Dr E Deltz, Dept of General Surgery, University of Kiel, Kiel, FRG. positive cells in the ileum. ${ }^{7}$ The effects of endogenous CCK are influenced by different cholinergic mechanisms. ${ }^{8}$ Intact vagal innervation is important for the motility and the effect of NT on the gastrointestinal tract of the rat. ${ }^{\theta}$ Intramural vasoactive intestinal peptide (VIP), which is released by preganglionic cholinergic excitatory fibres, influences villous microcirculation by regulating precapillary vessels. ${ }^{112}$ The morphological pattern of the cells containing and releasing these enteroendocrine regulatory peptides, ${ }^{13}$ including the distribution and the quantity within the small bowel wall, reflects the results of this complicated interplay between the various agents influencing the adaptive response and functional capacity of the mucosa. Small bowel transplantation must be regarded as a procedure that causes severe disturbances in the secretory and absorptive capacity of the mucosa. The recovery of these functions and the adaptation to the recipient's environment is, however, decisive for a successful outcome of SBT. Small bowel transplantation in the rat $^{14}$ provides a model for investigating the adaptive 
response of a transplanted small bowel. The graft is at least temporarily denervated and thus deficient in stimuli from the extrinsic autonomous nerves. Therefore this model reveals the sole influence of chymus stimulation on mucosal growth under the conditions of an intact intrinsic nervous system. The influence of enteral stimuli on the mucosa of the transplanted small bowel might be reflected in mucosal growth and in the morphological pattern of the enteroendocrine cells in the mucosa and in other layers of the bowel wall. These were the aspects upon which we based our investigation of the morphological pattern of enteroendocrine cells in the transplanted small bowel in the rat model.

\section{Methods}

\section{ANIMALS}

Orthotopic SBT was performed in the rat using a method described previously. ${ }^{14}$ The operative procedure consists of two steps. First the small intestine is transplanted heterotopically and accessory to the recipient's small bowel. Thus it is completely deprived of neural connections and is shunted off from the intestinal passage, being connected to the recipient only by the vascular anastomoses. After three weeks, when the lymph vessels of the graft have become connected to the recipient's lymph vessels, the graft is inserted into the recipient's gastrointestinal tract following resection of the recipient's small bowel. Thus the continuity of the alimentary tract is reestablished by the orthotopically placed graft.

EXPERIMENTAL GROUPS

LEW rats were used for all experiments. The controls (group 1, $n=5$ ) consisted of animals upon whom sham operations had been performed. Syngeneic heterotopic SBT was performed in the animals in group $2(n=7)$. In group $3(n=6)$ the small bowel graft was brought into orthotopic position three weeks after heterotopic transplantation. On day 20 (group 2) and day 40 (group 3) p. op. samples of jejunum and ileum were collected, and the tissue was fixed in Bouin's solution and embedded in wax.
Microsections were stained with rabbit anti-rat antibodies (Immunonuclear Corporation, Stillwater, Minn., USA). The cells producing the hormones cholecystokinin (CCK), neurotensin (NT) and vasoactive intestinal peptide (VIP) were stained, and the bound antibodies were localized with the peroxidaseanti-peroxidase method ${ }^{15}$ and counterstained with haemotoxylin. The number of cells/villus, the number of cells/length of lamina muscularis [mm] and the quantity of VIP positive fibres were measured by counting 20 high power fields in a videomat system (Kontron, Germany). In a given bowel segment the cells of at least 250 villi were counted.

\section{Results}

The results are shown in the Table. In contrast with the small bowel of the recipient, for which the data were comparable to the controls, the heterotopically transplanted small bowel (group 2) showed a significant decrease in the number of CCK positive cells (Fig. 1a) in both the jejunum and the ileum. The quantity of VIP positive fibres (Fig. 1c) in the graft decrease markedly in both jejunum and ileaum. The villi and crypts of the graft were slightly atrophied, compared with the small bowel of the recipient and the controls. After insertion of the graft into the continuity of the gastrointestinal tract (group 3) the pattern of hormone distribution changed clearly. There was a marked increase in CCK positive cells in jejunum and ileum and of NT positive cells in the ileum, exceeding the values in the controls by 20 $40 \%$. The quantity of VIP positive fibres also increased, but did not reach the quantity in the normal unaltered recipient's gut before resection. In accordance with these findings, the mucosa of the orthotopically transplanted small bowel no longer showed any signs of atrophy.

\section{Discussion}

Our results clearly show that the enteroendocrine cells of the mucosa of the transplanted small bowel are dependent on enteral stimuli that may be regarded as

Table Numbers of immunostained cells/villus (*) and numbers of cells/length of lamina muscularis (†), of CCK and NT, and quantity of VIP positive fibres in the jejunum and ileum

\begin{tabular}{|c|c|c|c|c|c|c|c|c|c|c|c|c|c|c|c|c|c|c|c|c|}
\hline & \multicolumn{5}{|c|}{$\begin{array}{l}\text { Controls } \\
\text { (Sham operation) }\end{array}$} & \multicolumn{5}{|c|}{$\begin{array}{l}\text { Recipient's } \\
\text { small bowel }\end{array}$} & \multicolumn{5}{|c|}{$\begin{array}{l}\text { Heterotopic } \\
\text { graft }\end{array}$} & \multicolumn{5}{|c|}{$\begin{array}{l}\text { Orthotopic } \\
\text { graft }\end{array}$} \\
\hline & ${ }^{*}$ CCK & $t$ & ${ }^{*}$ NT & $\dagger$ & VIP & ${ }_{*}^{\mathbf{C C K}}$ & + & ${ }^{\text {NT }}$ & + & VIP & $\begin{array}{l}\text { CCK } \\
*\end{array}$ & + & $\begin{array}{l}\text { NT } \\
*\end{array}$ & $\dagger$ & VIP & ${ }^{\text {CCK }}$ & + & $\begin{array}{l}\text { NT } \\
*\end{array}$ & $\dagger$ & VIP \\
\hline Jejunum & 1,2 & 0,7 & & 0 & $\uparrow \uparrow \uparrow$ & 1,0 & 0,7 & & 0 & $\uparrow \uparrow \uparrow$ & 0,6 & 0,5 & & 0 & $\uparrow$ & 1,4 & 1,0 & & 0 & $\uparrow \uparrow$ \\
\hline Ileum & 0,5 & 0,2 & 0,5 & 0,2 & $\uparrow \uparrow \uparrow$ & 0,4 & 0,2 & 0,4 & 0,1 & $\uparrow \uparrow \uparrow$ & 0,3 & 0,1 & 0,4 & 0,1 & $\uparrow$ & 0,7 & 0,4 & 0,5 & 0,3 & $\uparrow \uparrow$ \\
\hline
\end{tabular}

* numbers of cells/villus; † numbers of cells/length of lamina muscularis [mm]. 


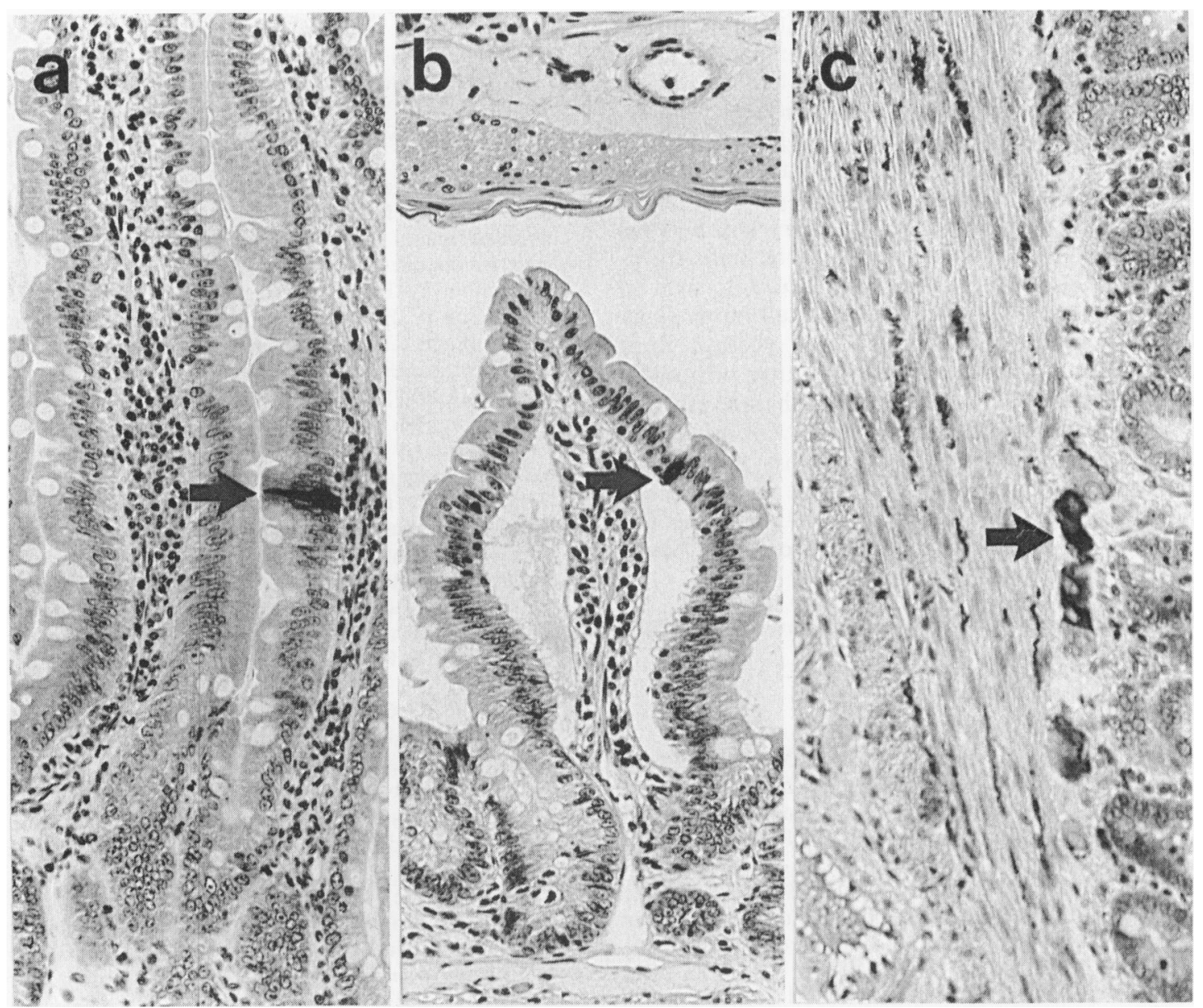

Fig. 1 Immunostained cells $(\rightarrow)$ of the small bowel graft containing CCK (a) jejunum, and NT (b) ileum, and VIP positive fibres $(\rightarrow)$ (c) lamina muscularis, jejunum.

analogous to the findings after jejunoileal bypass experiments. ${ }^{6}$ Alterations in the enteroendocrine cells occur to a striking extent in both segments investigated by us (jejunum and ileum). Cholecystokinin positive cells in the jejunum and ileum of heterotopic grafts decrease by about $30-40 \%$, compared with the recipient's small bowel. A similar decrease could be shown in the quantity of VIP positive fibres. These results are comparable with those of Buchan et al, ${ }^{7}$ who pointed out a distinct reactivity of CCK cells in duodenum and jejunum by showing a marked decrease in these cells after total parenteral nutrition. These authors also showed an increase in NT positive cells in the ileum after TPN. In SBT NT positive cells did not show a similar reaction to deficient luminal stimuli in the heterotopic position. After having been brought into orthopic position with continuous luminal stimuli, the number of enteroendocrine cells not only reached normal values, but even exceeded normal cell counts. CCK positive cells in jejunum and ileum exceeded normal values by $20-40 \%$. The number of NT positive cells reached normal values. Vasoactive intestinal peptide positive fibres, however, did not show the same pattern as normal control sections do. Our results show that CCK positive cells and CCK dependent enteroendocrine regulatory mechanisms, and to a lesser extent NT positive cells, are highly reactive in this system of SBT with different degrees of exposure of the small bowel mucosa to luminal stimuli. Schwartz et $a^{16}$ were able to show an increase in the absorptive capacity of the rat small intestine after systemic application of CCK. In our experiments the paracrine or endocrine effects of CCK release in the mucosa may contribute to the reversal of mucosal atrophy that can be observed after orthotopic interposition of the graft. The 
increased absorptive capacity of the orthotopic graft $^{17}$ could therefore be explained in part by CCK effects. In summary, we can show that luminal stimuli, including pancreatic and bile secretion, are responsible for the adaptive response following SBT. The luminal stimuli may reactivate the enteroendocrine cells in the mucosa of the small bowel graft. The interaction of these cells with the intrinsic nervous system of the small bowel seems to be sufficient to stimulate adaptation and mucosal growth to such an extent that after SBT unimpaired small bowel function is possible. ${ }^{17}$ The fact that VIP positive fibres did not show a complete recovery after orthotopic transplantation seems to be evidence that the intrinsic nervous system of the small bowel wall might not have been reconnected with the extrinsic nerve fibres of the autonomous nervous system. Therefore extrinsic innervation of the small bowel graft does not seem to be necessary for adequate small bowel function after transplantation.

We are indebted to Ms Jutta Quitzau for excellent technical assistance.

\section{References}

1 Sagor GR, Al-Mukhtar MYT, Ghatei MA, Wright NA, Bloom SR. The effect of altered luminal nutrition on cellular proliferation and plasma concentrations of enteroglucagon and gastrin after small bowel resection in the rat. Br J Surg 1982; 69: 14-18.

2 Sagor GR, Ghatei MA, Al-Mukhtar MYT, Wright BA, Bloom SR. Evidence for a humoral mechanism after small intestinal resection. Gastroenterology 1983; 84: 902-6.

3 Dowling RH, Miazza BM. Potentiel d'adaption du tractus gastrointestinal existence d'un axe tropique entéro-pancréatique, role des hormones et polyamines. Schweiz Med Wochenschr 1985; 115: 963-70.

4 Al-Mukhtar MYT, Sagor GR, Ghatei MA, Bloom SR, Wright NA. The role of pancreatico-biliary secretions in intestinal adaptation after resection, and its relationship to plasma enteroglucagon. Br J Surg 1983; 70: 398400.
5 Buchan AMJ, Griffiths CJ, Morris JF, Polak JM. Enteroglucagon cell hyperfunction in rat small intestine after gut resection. Gastroenterology 1985; 88: 8-12.

6 Buchan AMJ, Pederson RA, Chan CB, Brown JC. The effect of massive small bowel resection (MSBR) and small intestinal bypass (JIB) in the rat on the enteroinsular axis. Regulatory Peptides 1983; 7: 221-32.

7 Buchan AMJ, Innis SM, Pederson RA. The effect of total parenteral nutrition in the rat on a sub-group of enteroendocrine cells. Gastroenterology 1985; 88: 1138.

8 Sakamoto T, Fujimura M, Mate L, Greeley GH, Thompson JC. Effect of vagotomy on pancreatic protein secretion and gallbladder emptying in response to endogenous or exogenous CCK stimulation in dogs. Gastroenterology 1985; 88: 1566.

9 Hellström PM. Vagal interaction on the effect of neurotensin on gastrointestinal propulsion in the rat. Gastroenterology 1985; 88: 1416.

10 Thomson JC, Marx M. Gastrointestinal hormones. Current problems in surgery. INO. Chicago: Year Book Medical Publishers, 1984: 38.

11 Holliger $\mathbf{C H}$, Radzyner M, Knoblauch M. Effects of glucagon, vasoactive intestinal peptide, and vasopressin on villous microcirculation and superior mesenteric artery blood flow of the rat. Gastroenterology 1983; 85: 1036-43.

12 Forssmann WG, Reinecke M. Morphofunctional anatomy of disseminated endocrine cells related to the regulation of precapillary vessels. $J$ Cardiovasc Pharmacol 1984; 6: 354-64.

13 Grube D, Forssmann WG. Morphology and function of the entero-endocrine cells. Horm Metab Res 1979; 11 : 589-606.

14 Deltz E, Thiede A. Microsurgical technique for small intestine transplantation. In: Thiede A, Deltz E, Engemann R, Hamelmann H, eds. Microsurgical models in rats for transplantation research. Berlin: Springer Verlag, 1985: 51-5.

15 Sternberger L. Immunocystochemistry. New York: Wiley, 1979.

16 Schwartz MZ, Storozuk RS. Can gastrointestinal hormones enhance intestinal absorption. Surgery 1985; 98: 430-6.

17 Schroeder P, Deltz E, Preissner Ch, Seifert J, Sandforth F, Thiede A. Absorption capacity of the transplanted small bowel. Gut 1987; 28: S275-9. 